\title{
Effect of the Brazilian Cardioprotective Nutritional Program on the Quality of Life of Atherosclerotic Disease Patients
}

\author{
Patrícia Regina Thomé Martins, ${ }^{1}$ Annie Seixas Bello Moreira, ${ }^{1}$ Elisa Maia dos Santos, ${ }^{1 \oplus}$ Luiz Fernando \\ Rodrigues Júnior, ${ }^{1,2}$ Bernadete Weber ${ }^{3}$ \\ Department of clinical Research, National Institute of Cardiology (INC), ${ }^{1}$ Rio de Janeiro, RJ - Brazil \\ Department of Physiological Sciences, Biomedical Institute of the Federal University of the State of Rio de Janeiro (UNIRIO), ${ }^{2}$ Rio de Janeiro, RJ - Brazil \\ Research Institute, Heart Hospital (HCor), ${ }^{3}$ São Paulo, SP - Brazil
}

\section{Abstract}

Background: Cardiovascular diseases (CVD) accounted for 27\% of deaths in Brazil in 2017. Most of the recorded deaths caused by CVD would be preventable if patients controlled risk factors including inadequate diet. The Brazilian Cardioprotective Nutritional Program (Dica Br) adapted the Mediterranean diet pattern to Brazilian typical foods and evaluated the effectiveness of a nutritional program based on cardioprotective foods on cardiovascular events and death of patients with cardiovascular diseases.

Objectives: To evaluate the effect of Dica Br on the QoL of patients with atherosclerotic disease from two health centers in the city of Rio de Janeiro.

Method: Randomized clinical trial with 273 participants of both sexes, over 45 years old, followed for four years. The intervention group (IG) received individualized dietary prescription, educational program, individual and group consultations, and phone calls. The control group (CG) received general dietary guidance. The SF-36 was used to assess QoL. The Student's t-test and the Mann-Whitney test was used to compare means between the groups. The mixed model test was used to compare the course of variables over time between the groups. Statistical significance was set at $5 \%$.

Result: Most patients were male, with an average age of $64.2 \pm 8.2$ years in the IG and $65 \pm 9.5$ years in the CG. Most were physically inactive, overweight, and had incomplete elementary school. The most prevalent comorbidity was systemic arterial hypertension, followed by dyslipidemia. QoL improved in both groups at four years. Waist circumference decreased in both groups over time, and low-density lipoprotein cholesterol (LDL-C) levels decreased in the IG but not in the CG after four years of follow-up.

Conclusion: The cardioprotective diet was effective in reducing LDL-C in the IG, and an improvement in QoL was observed in both intervention and control groups.

Keywords: Quality of life; Diet, Atherosclerosis; Cardiovascular diseases; Disease Prevention.

\section{Introduction}

Cardiovascular diseases (CVD) accounted for $45 \%$ of deaths in the world in 2015, causing a great impact on statistics. ${ }^{1}$ In Brazil, mortality rates from diseases of the circulatory system are also high and represented $28 \%$ of deaths in $2017 .{ }^{2}$ Therefore, CVD is considered a major public health problem. Most of the recorded deaths caused by CVD would be preventable if patients followed the prescribed medical treatment and controlled risk factors, including inadequate diet, smoking, obesity, physical inactivity, high blood pressure and high cholesterol levels. ${ }^{3}$

CVDs are debilitating conditions, with a progressive course and multiple factors, such as physical limitation and risk of death, that affect the improvement of the 
diseases and patients' quality of life (QoL). ${ }^{4} \mathrm{~A}$ poor QoL is associated with depression, social exclusion, anxiety, and consequently worsening of diseases, leading to an increased use of medications and increased incidence of CVD, leading to a vicious cycle..$^{5-7}$

The main risk factor for CVDs is unhealthy eating, and the relationship between dietary patterns and the disease has been studied in recent years. One of these patterns, called the "western diet", is rich in total fats, cholesterol and refined sugar, and poor in dietary fiber. It is closely related to a sedentary lifestyle and the occurrence of chronic non-communicable diseases. ${ }^{8-10}$ Meanwhile, the Mediterranean $\operatorname{diet}^{11-14}$ has been shown to have a consistent and positive association with cardiovascular and metabolic health, ${ }^{9,15,16}$ as well as with higher rates of QoL. ${ }^{17,18}$

The multicenter clinical trial Dica $\mathrm{Br}$ evaluated the effectiveness of implementing a nutritional program based on cardioprotective foods on cardiovascular events and death in patients with established CVD. The trial adapted the Mediterranean diet pattern to Brazilian typical foods that are easily accessible, low cost, and clearly prescribed, respecting regional characteristics, thus favoring adherence by the Brazilian population. ${ }^{19-22}$

The objective of this study was to assess the effects of the Dica Br on the QoL and nutritional status of participants over a four-year follow-up period.

\section{Methods}

\section{Study Design}

This is a randomized clinical trial conducted at the National Institute of Cardiology (INC) and at the Piquet Carneiro Polyclinic (PPC-UERJ). This study is an integral part of the Dica Br, whose design has been described and published previously. ${ }^{20}$

The study protocol was approved by the Research Ethics Committees of the INC and the Pedro Ernesto University Hospital of the State University of Rio de Janeiro (HUPE), in accordance with Resolution No. 466 of December 12, 2012, of the National Health Council (approval numbers 03218512.0.2006.5272 and 03218512.0.2002.5259, respectively). All participants were informed about the procedures and signed an informed consent form.

The participants received personalized dietary guidance and food calorie distribution according to the Dica Br food groups. They also received educational guidance, individual and group consultations, and a cookbook. The control group received a generalized guidance only, with a list of foods to be avoided, and no caloric value.

\section{Participants}

The trial was initially carried out with 273 participants from two study centers. Inclusion criteria were adults of both sexes, aged 45 or over; with previously documented CAD, stroke, myocardial revascularization and/or angioplasty, peripheral arterial disease, or hospitalization for unstable angina.

Exclusion criteria were inability to eat by mouth; clinical suspicion or diagnosis of hepatic encephalopathy or other liver diseases; cancer patients; patients who underwent gastroplasty; patients with previous organ transplantation; wheelchair users; patients in the immediate postoperative period of cardiac surgery (up to 30 days after surgery); patients diagnosed with heart failure at any stage of the disease.

\section{Randomization}

Eligible participants were randomly assigned (1: 1) to the intervention group (IG) or the control group (CG). Randomization was performed in blocks with stratification by study location. The allocation concealment was guaranteed through an automated centralized system, available on the web 24 hours a day.

\section{Intervention}

The intervention consisted of three components: (a) dietary prescription; (b) educational program based on playful educational strategies and suggestions of food choices; and (c) individual interviews, group sessions and contact by telephone. Participants received a booklet with information on the diet they should follow, including caloric value, distribution, portions and food groups, recipes, tips and general information about the program, in addition to the cookbook.

The foods were divided into three groups according to the following criteria: no added sugar; low calories; no nutrients that increase cardiovascular risk (cholesterol, saturated fat, and sodium), and the presence of cardioprotective nutrients (antioxidants and fibers). This qualitative selection generated a list containing skim milk and yogurt, fruits and vegetables, and beans. This group was called "green". The cutoff point was established based on a caloric density $\leq 1.11 \mathrm{kcal} / \mathrm{g}$, fatty 
acids $\leq 0.001 \mathrm{~g} / \mathrm{g}$, cholesterol $\leq 0.04 \mathrm{mg} / \mathrm{g}$ and sodium $\leq 2.01$ $\mathrm{mg} / \mathrm{g} .{ }^{23}$ Foods containing one or two nutrients above the cutoff point were allocated to the yellow group, and those containing three or four nutrients above the cutoff point were categorized in the blue group.

The green color occupies the greatest area on the flag, which correlates with the green food group that should be consumed in greater quantity. Yellow comes in second place, suggesting a lower intake, and the blue, which is in a small part, an even more restricted intake. The red group consists of foods containing trans fat, refined sugar, artificial sweeteners and preservatives, as well as ultra-processed foods, and their consumption has been totally discouraged. As the red group is not shown on the flag, the food in that group should not be consumed.

The total energy value (TEV) was calculated using the formula of $20 \mathrm{kcal} / \mathrm{kg}$ of the current weight for weight loss (obesity and overweight), and $25 \mathrm{kcal} / \mathrm{kg} /$ weight for normal-weight patients..$^{20}$ Aiming to promote adherence to the diet, dietary prescriptions contained the numbers of food portions of the green, blue and yellow groups by meals. All participants were seen individually every six months. In the first two years, once a month, participants received a telephone call to reinforce their understanding of the program and reinforce dietary points. In the third and fourth years they received a call every four months. Participants also attended group meetings every four months, from the $28^{\text {th }}$ to the $44^{\text {th }}$ month, with lectures with topics on nutritional and motivational education prepared by the program to increase adherence.

\section{Control}

Participants were instructed to follow a diet based on low-fat and low-sodium foods. They all received a folder containing a list of foods that should be avoided and foods that should be preferred. It was a qualitative diet, without calculation of the TEV. Caloric restriction was made by replacing high-energy-density foods by low-energy-density foods. These participants were seen in face-to-face, individual sessions every six months for four years. Anthropometric data and blood samples were collected, the 24-hour food recall was applied and information on lifestyle habits and QoL was collected.

\section{Study steps}

During their half-yearly visits to the data collection sites, participants underwent individual interviews, blood collection for biochemical analysis, anthropometric analysis, physical activity assessment questionnaire, a 24-hour dietary recall, and the Medical Outcomes Study 36-item Short-Form Healthy Survey (SF-36) questionnaire, and received guidance regarding diet, as shown in Figure 1.

\section{Sample}

A convenience sampling was used to recruit 273 patients in the two study centers, over the period of one year.

\section{Anthropometric assessment}

Body weight was measured in kilograms $(\mathrm{kg})$, using an electronic body weight scale (Líder®) with a stadiometer, with a maximum of $200 \mathrm{~kg}$, precision of 100 $\mathrm{g}$ and accuracy of $1 \mathrm{~mm}$, positioned on a flat surface. The patients were weighed barefoot. Height was measured in meters (m), with participants barefoot, with the head in the Frankfurt plane, and arms extended along the body. Weight and height measurements were used to calculate the body mass index (BMI).

Waist circumference (WC) was measured with a flexible, inelastic measuring tape to the nearest 0.1 $\mathrm{cm}$, with the subject in an upright position, abdomen relaxed, arms alongside the body and feet together. The measurement was taken at the midpoint between the last rib and the iliac crest, and the result expressed in centimeters $(\mathrm{cm})$.

\section{Biochemical evaluation}

Blood collection was performed by a trained technician, after a 12-hour fast. Blood samples were collected in a tube containing coagulant. After 30 minutes of coagulation at room temperature, they were centrifuged at $4000 \mathrm{rpm}$ for 15 minutes to obtain serum. The samples obtained were analyzed by the hospital biochemical analysis laboratory on the same day of collection.

\section{Quality of Life Assessment}

To assess QoL, the SF-36 questionnaire ${ }^{24,25}$ was used. This questionnaire was chosen because it is more extensive and not specific to a given population. It consists of 36 items distributed in eight domains: functional capacity, physical aspects, pain, general health, vitality, emotional aspect, social aspect, and mental health. Domains 1 to 4 deal with physical aspects, while domains 5 to 8 measure 


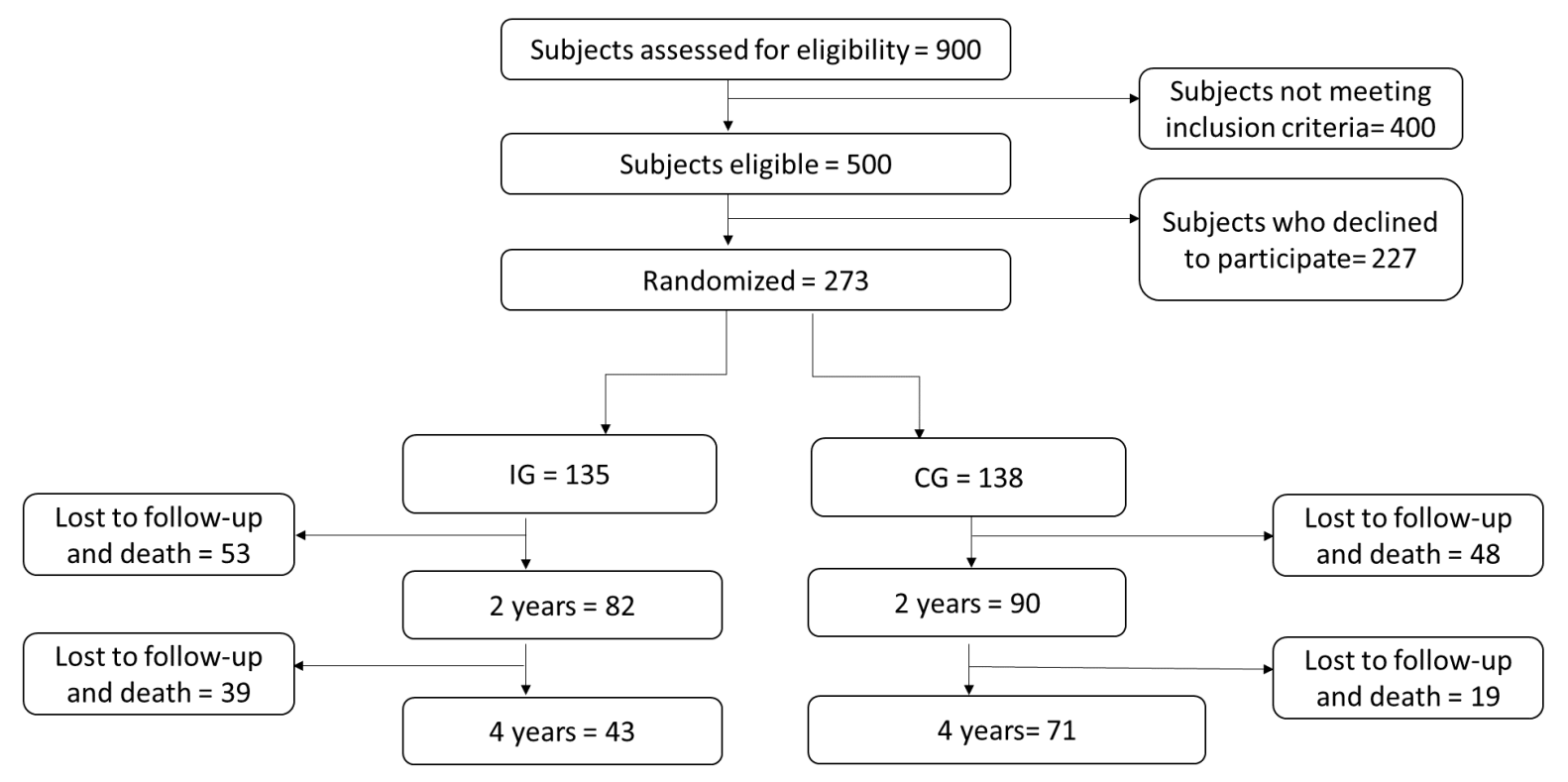

Figure 1 - Flowchart of patient selection.

emotional characteristics. For each parameter, the scores were coded, added and transformed on a scale from 0 (the worst possible condition) to 100 (the best possible condition). In the case of body pain domain, a score of 100 means complete tolerance or absence of pain. Each dimension is analyzed separately, there is no single value that summarizes the entire assessment, translating into a better or worse general health condition. The purpose is to avoid, on an average of values, failure to identify the actual problems related to the interviewee's QoL and health, or underestimate them. For the analysis of the SF-36 questionnaire, the free app Qualipes, available at https://app.qualipes.com.br, was used.

\section{Financial resources}

This study was funded by the Heart Hospital (HCor), as part of the program "Hospitals of Excellence in Health Services (PROADI-SUS)", in partnership with the Ministry of Health of Brazil.

\section{Statistical analysis}

The data were evaluated using the statistical program Statistical Package for the Social Sciences ${ }^{\circledR}$ (SPSS) version 23.0 (SPSS Incorporation), GraphPad Prism version 8.3.0.538 and Stata Corp LLC (Stata 13) Texas, USA. Data are expressed as mean (standard deviation) for variables with normal distribution, median (P2575) for nonparametric variables, and percentages for dichotomous variables. The Kolmogorov-Smirnov normality test was used to verify the distribution the continuous variables. The chi-square test was used to compare dichotomous variables. The student's t-test or the Mann-Whitney $U$ test was used to compare means between the groups. Differences in the responses of QoL domains between different intervention protocols (control and intervention groups) were evaluated by linear mixed models,26,27 with the inclusion of the variables time, protocol, and interaction term (time* protocol), which estimates the response rate of the outcome over time (term of interest). The significance value was set at 5\%.

\section{Results}

Two hundred seventy-three subjects started the study, but only 114 reached the end, representing a percentage loss of $58.3 \%$. Subjects were diagnosed with atherosclerotic disease documented in medical records, 142 of whom were followed at the INC and 131 at the PPC. They are all part of the national multicenter study entitled "Effect of the Brazilian Cardioprotective Nutritional Program to reduce events and risk factors in secondary prevention for cardiovascular disease: a randomized clinical trial". 
Nine hundred medical records were selected, of which 400 did not meet the eligibility criteria. Of this total, 273 patients agreed to participate in the trial. After electronic randomization, the subjects were divided into two groups, 135 in the IG and 138 in the CG. In the second year of the study, there were 53 dropouts or deaths in the IG and 48 in the CG. At the end of the study, 43 subjects in the IG and 71 in the CG had completed it, that is, a percentage of $32 \%$ and $71 \%$ respectively (Figure1).
Table 1 compares the subjects who completed the trial and those who dropped out. Besides having similar quality of life scores, no differences were found in age, weight, sex, BMI, education and physical activity between these subgroups. Those who dropped out had higher HDL, lower cholesterol and glucose levels.

Table 2 shows general characteristics of participants by study group. Mean age of CG was $64.2 \pm 8.2$ years and 65 \pm 9.5 years in the IG. Most participants were male $(82 \%$ in the CG and $63.7 \%$ in the IG), physically inactive $(65.2 \%$

Table 1 - Comparison of demographical, laboratory and quality of life data between participants who finished and dropped out of the study

\begin{tabular}{|c|c|c|c|}
\hline Variables & Finished & Dropped out & p \\
\hline n $(\%)$ & $114(42 \%)$ & $159(58 \%)$ & \\
\hline Age (years) ${ }^{b}$ & $64.15 \quad \pm 7.61$ & $64.95 \quad \pm 9.69$ & 0.720 \\
\hline Weight $^{b}$ & $76.88 \quad \pm 14.48$ & $77.04 \quad \pm 15.24$ & 0.459 \\
\hline Body mass index ${ }^{\natural}$ & $29.6 \quad \pm 4.80$ & $29.40 \quad \pm 5.23$ & 0.664 \\
\hline Gender - male ${ }^{\ddagger}$ & $61.06(69)$ & $61.88(99)$ & 0.892 \\
\hline Marital status - married ${ }^{+}$ & $52.68(59)$ & $53.46(85)$ & 0.668 \\
\hline Incomplete elementary school ${ }^{t}$ & $28.57(32)$ & $33.96(54)$ & 0.430 \\
\hline Physically inactive ${ }^{\ddagger}$ & $67.86(76)$ & $70.51(110)$ & 0.642 \\
\hline Ex-smoker ${ }^{\dagger}$ & $62.73(69)$ & $54.84(85)$ & 0.439 \\
\hline Ex-alcoholic ${ }^{\dagger}$ & $37.50(42)$ & $35.48(55)$ & 0.629 \\
\hline Total cholesterol (mg/dL)" & $167.0(138.5-206.0)$ & $170.5(137.0-205.2)$ & 0.792 \\
\hline LDL-C (mg/dL) & $91.0(74.0-118.5)$ & $94.5(72.8-122.0)$ & 0.641 \\
\hline HDL-C (mg/dL) & $39.0(33.0-45.0)$ & $44.0(36.0-55.5)$ & $0.001^{*}$ \\
\hline Triglycerides (mg/dL)' & $152.0(104.5-207.5)$ & $114.0(88.5-165.5)$ & $0.000^{*}$ \\
\hline Glucose (mg/dL)" & $122.0(102.0-166.0)$ & $108.5(97.3-134.0)$ & $0.001^{*}$ \\
\hline Glycated hemoglobin (\%)" & $6.7(5.8-8.2)$ & $6.0(5.7-6.7)$ & $0.000^{*}$ \\
\hline Physical functioning, & $53(30-75)$ & $55(30-85)$ & 0.454 \\
\hline Role physical" & $25(90-75)$ & $50(0-81)$ & 0.441 \\
\hline Bodily pain" & $52(31-72)$ & $51(30-84)$ & 0.860 \\
\hline General health" & $67(42-87)$ & $67(49-82)$ & 0.839 \\
\hline Vitality" & $60(35-80)$ & $65(40-80)$ & 0.443 \\
\hline Social functioning, & $75(50-100)$ & $75(50-100)$ & 0.401 \\
\hline Role emotional' & $100(0-100)$ & $66(33-100)$ & 0.481 \\
\hline Mental health" & $76(48-88)$ & $72(52-85)$ & 0.750 \\
\hline
\end{tabular}


Table 2 - General characteristics of study participants by randomization group

\begin{tabular}{|c|c|c|c|}
\hline Variable (n) & Control group & Intervention group & $\mathrm{p}$ value \\
\hline $\mathrm{n}$ & 138 & 135 & \\
\hline Age (years) ${ }^{\natural}$ & $64.2( \pm 8.2)$ & $65( \pm 9.5)$ & 0.448 \\
\hline Gender - male $\%(n)^{\ddagger}$ & $82(59.4)$ & $63.7(86)^{4}$ & 0.535 \\
\hline Marital status - married $\%(n)^{\ddagger}$ & $55.1(76)$ & $51.13(68)$ & 0.647 \\
\hline Incomplete elementary school $\%(n)^{\ddagger}$ & $33.3(46)$ & $30.01(40)$ & 0.649 \\
\hline Physically inactive $\%(n)^{\ddagger}$ & $65.2(90)$ & $73.85(96)$ & 0.116 \\
\hline Ex-smoker ${ }^{\dagger}$ & $60.6(83)$ & $55.5(71)$ & 0.595 \\
\hline Ex-alcoholic ${ }^{p}$ & $39.0(53)$ & $35.6(44)$ & 0.398 \\
\hline Overweight $\%(n)^{+}$ & $46.7(63)$ & $38.7(53)$ & 0.434 \\
\hline Hypertension $\%(n)^{t}$ & $95.6(131)$ & $97.0(131)$ & 0.535 \\
\hline Dyslipidemia \% (n) ${ }^{\sharp}$ & $94.2(129)$ & $88.1(119)$ & 0.159 \\
\hline Diabetes mellitus \% (n) ${ }^{\natural}$ & $54.7(75)$ & $53.3(72)$ & 0.596 \\
\hline Acute heart attack $\%(n)^{\ddagger}$ & $62.8(86)$ & $67.4(91)$ & 0.427 \\
\hline Angina $\%(n)^{\natural}$ & $51.1(70)$ & $54.8(74)$ & 0.438 \\
\hline Myocardial revascularization surgery $\%(n)^{\ddagger}$ & $43.8(60)$ & $42.2(57)$ & 0.793 \\
\hline Weight $(\mathrm{kg})^{\mathrm{b}}$ & $77.3( \pm 14.5)$ & $78.4( \pm 15.4)$ & 0.548 \\
\hline Waist circumference $(\mathrm{cm})^{\mathrm{b}}$ & $100.8( \pm 13.2)$ & $100.7( \pm 12.2)$ & 0.934 \\
\hline Total cholesterol, & $171(137-206.7)$ & $165.5(140.2-204)$ & 0.534 \\
\hline HDL-C & $40(33-48)$ & $40(34-50)$ & 0.958 \\
\hline LDL-C, & $94(73-119)$ & $94(76-120)$ & 1 \\
\hline Triglycerides (mg/dL)" & $130.5(96.5-191.2)$ & $141(95-201)$ & 0.418 \\
\hline Glucose (mg/dL) & $117(101.50-153)$ & $113(99.5-153.5)$ & 0.802 \\
\hline Glycated hemoglobin (\%)" & $6.3(5.7-7.5)$ & $6.3(5.8-8.2)$ & 0.751 \\
\hline Physical functioning, & $55(37.50-80)$ & $50(30-75)$ & 0.945 \\
\hline Role physical & $25(0-100)$ & $25(90-75)$ & 0.680 \\
\hline Bodily pain" & $51(31-74)$ & $52(30-72)$ & 0.856 \\
\hline General health" & $67(46-83.50)$ & $67(45-87)$ & 0.966 \\
\hline Vitality" & $60(37.50-80)$ & $60(40-80)$ & 0.578 \\
\hline Social functioning" & $75(50-100)$ & $75(50-100)$ & 0.497 \\
\hline Role emotional, & $66(0-100)$ & $100(33-100)$ & 0.364 \\
\hline Triglycerides (mg/dL)" & $72(52-88)$ & $72(48-88)$ & 0.953 \\
\hline
\end{tabular}


CG and $73.8 \%$ IG), and $33.3 \%$ in the CG and 30\% in the IG had incomplete elementary education. Among the most reported diseases, systemic arterial hypertension was the most prevalent ( $97 \%$ of patients in the IG and $95.6 \%$ in the CG), followed by dyslipidemia $(88.1 \%$ in the IG and $94.2 \%$ in the CG). A high rate of overweight, a known risk factor for CVD, was found among study participants of both groups. No difference in QoL scores or in any other variable was found between the groups.

Figure 2 shows the impact of the intervention on anthropometric and biochemical data over the four years of study. Although no changes in body weight and BMI were observed in the groups, WC showed a significant reduction over time, with no statistical difference between the groups though. LDL and total cholesterol levels significantly reduced in the IG but not in the CG, leading to a significant difference between the groups. Glycated hemoglobin levels also decreased in the IG, and no differences in HDL, triglycerides or glucose levels were observed between the groups.

Figure 3 shows the graphs with the analysis of the QoL scores. All domains and subdomains, except mental health, showed improvement over time, but no statistical difference was found between groups.

Table 3 presents the linear regression analysis of QoL domains in IG and CG at 2 and 4 years of follow-up. In the first analysis, results of the SF-36 were compared between the groups without adjustments, and in second the comparison, results were adjusted for BMI, age, and sex. No differences were found in neither analysis between groups over time.

\section{Discussion}

In recent years, eating patterns have changed in almost every nation in the world. At the same time, the science of nutrition has advanced remarkably. The importance of adopting an adequate dietary pattern for the prevention and treatment of atherosclerotic disease is clear.

The present study evaluated the effects of the cardioprotective diet on the QoL of atherosclerotic disease patients participating in the multicenter clinical trial Dica Br over four years of intervention. An improvement in the general QoL of participants was observed after the dietary intervention. Studies using dietary patterns have shown an improvement in QoL associated with improvements in the quality of the diet. ${ }^{28-30}$

Study participants were on average 65 years old, mostly married men with incomplete elementary education. We found some studies in the literature with a population similar to ours, but with a much higher number of participants, such as the study by
A

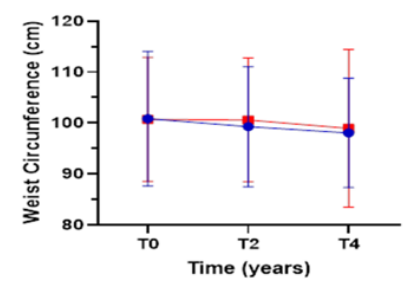

- Control

- Balance

B

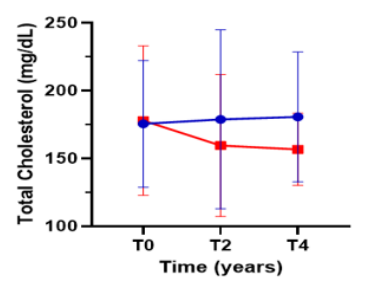

D

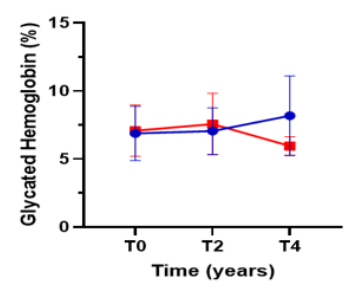

$\rightarrow$ Control

- Balance

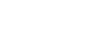

- Control

- Balance

Figure 2 - Graphs respresenting the analysis of waist circumference, total cholesterol,low-density lipoprotein (LDL)-cholesterol and glycated hemoglobin at baseline, two years and four years of follow-up in the intervention group and control group. A. waist circumference: time $=\mathrm{p}=0.0001$; group $\mathrm{p}=0.470$; time $x$ group $\mathrm{p}=0.1559 ; \mathrm{B}$. total cholesterol: time $\mathrm{p}=0.2048$; group $\mathrm{p}=0.1268 ;$ time $\mathrm{x}$ group $\mathrm{p}=0.0462$; C LDL: time $\mathrm{p}=0.3498$; group $\mathrm{p}=0.0437$; time $\mathrm{x}$ group $\mathrm{p}=0.0222 ; \mathrm{D}$ glycated hemoglobin: time $\mathrm{p}=0.7801 ;$ group $\mathrm{p}=0.2035 ;$ time $\mathrm{x}$ group $\mathrm{p}=0.0224$. Linear mixed model test 

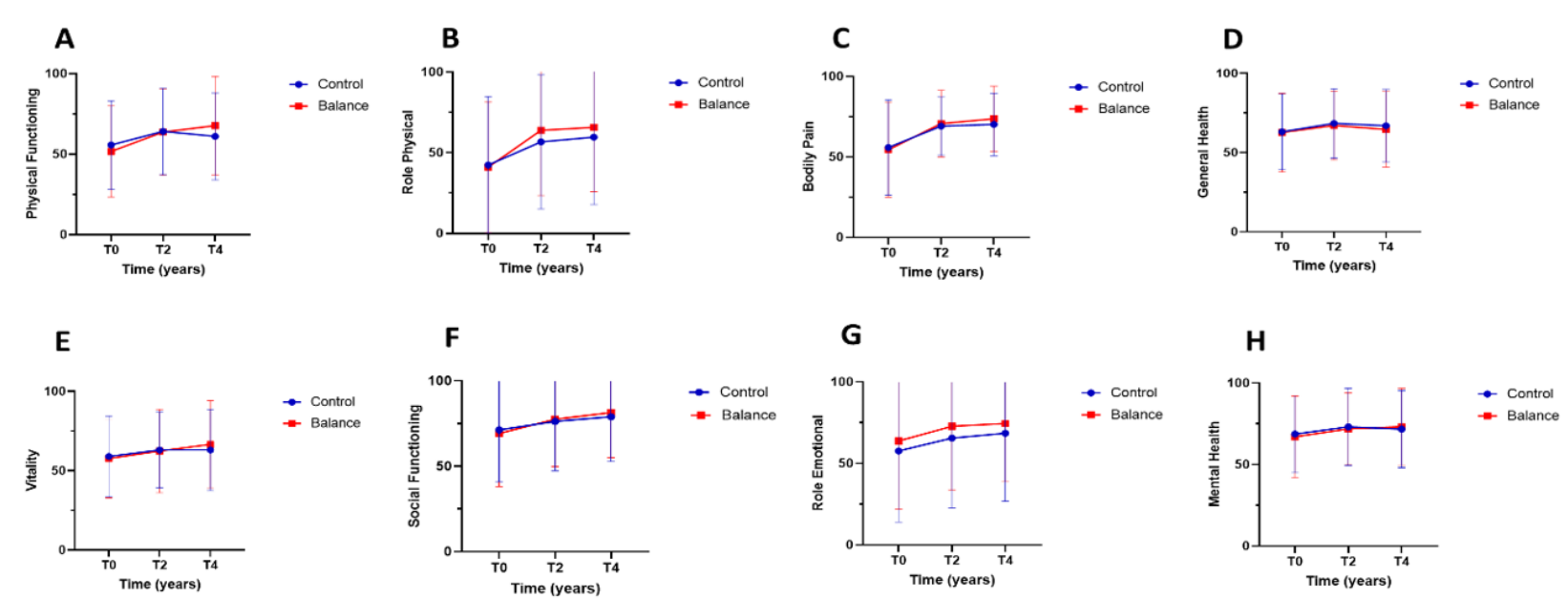

Figure 3 - Graphs representing the analysis of quality of life domains obser the four years of study. A physical functioning: time $p=0.0001$, group $p=0.9745$, time $x$ group $p=0,1613$; B role physical: time $p=0,0001$, group $p=0,3813$, time $x$ group $p=0,4102 ; C$ bodily pain: time $p=0,0001$, group $p=0,6404, T x G p=0,5727$; $D$ general health: time $p=0,0488$, group $p=0,5744$, time $x$ group $p=0,8771$; $E$ vitality: time $p=0,0329$, group $p=0,8942$, time $x$ group $p=0,7134$; $F$ social functioning: time $p=0,0009$, group $p=0,9025$, time $x$ group $p=0,6666$; $G$ role emotional: time $p=0,00086$, group $p=0,1449$, time $x$ group $p=0,9963 ; \mathrm{H}$ mental health: time $p=0,0542$, group $p=0,7604$, time $x$ group $\mathrm{p}=0,8802$. Lineal Mixed

Milte et al., ${ }^{31}$ in Australia, with 2,457 patients between 55 and 65 years old, where they evaluated adherence to a Mediterranean diet and association with QoL. ${ }^{31} \mathrm{In}$ the study by Pérez-Tasigchana et al. ${ }^{14}$ in Spain, 2,376 elderly people were enrolled, and most had completed high school; adherence to the Mediterranean diet was associated with QoL. ${ }^{14}$ Our study is part of the Dica Br study, ${ }^{19}$ and our population representative of the Dica Br program.

Our study focused on tertiary prevention in sample of CVD patients with hypertension, diabetes, and dyslipidemia as the most prevalent comorbidities. When performing the cardiovascular risk assessment using anthropometric and biochemical indices, we observed that our participants were classified as at increased risk. It is worth mentioning that all patients in the study presented a previous cardiovascular event, and most of them were overweight, physically inactive and hypertensive. Characteristics of our population were similar to that in the study by Jahangiry et al., ${ }^{32}$ in Iran, where most patients were overweight, had increased WC and hypertension.

WC is a simple measure that has a close correlation with central adiposity and is therefore a good marker of cardiovascular risk. In our study we found a significant reduction in WC in the participants of both intervention and control groups. Renzo et al., ${ }^{11}$ evaluating the effects of a dietary intervention in 188 subjects, for four weeks in Italy, demonstrated a decrease in gynoid body adiposity in the group that underwent intervention with an isocaloric Mediterranean diet.

In our study, the IG showed a significantly greater reduction in serum LDL-C levels after four years of intervention when compared to the CG. At the end of the study, total cholesterol and glycated hemoglobin showed differences between the groups. In their clinical trial, Castres et al..$^{33}$ also observed a decrease in serum LDL-C levels after six months of intervention with a balanced diet and a program of 10,000 steps per day. Estruch et al. ${ }^{13}$ found an increase in serum HDL-C levels in subjects undergoing a Mediterranean-style dietary intervention. In our study, the improvement in serum LDL-C levels in the IG can be justified by the recommendation to not consume ultra-processed products, in accordance with the guidelines for the treatment and prevention of dyslipidemia. ${ }^{15,16,34} \mathrm{In}$ addition, a guideline from the American College of Cardiology (ACC) and the American Heart Association (AHA), published in early 2019, points to lifestyle change as an extremely important item in the prevention and treatment of CVD. ${ }^{16}$ Then, in addition to dietary practices, other lifestyle changes such as regular exercise, smoking cessation, meditation 
Table 3 - Assessment of quality of life domains (SF-36 questionnaire) between the groups over the four years of the study

\begin{tabular}{|c|c|c|c|c|c|c|}
\hline \multirow[b]{2}{*}{ Variable } & \multicolumn{3}{|c|}{ Without adjustment } & \multicolumn{3}{|c|}{ Adjusted for BMI, age and sex } \\
\hline & $\beta$ & $95 \% \mathrm{CI}$ & $p$ value & $\beta$ & $95 \%$ CI & $p$ value \\
\hline \multicolumn{7}{|c|}{ Physical Functioning } \\
\hline Time 2 & 4.45 & -2.5211 .43 & 0.210 & 4.39 & $-2.58 \quad 11.37$ & 0.217 \\
\hline Time 4 & 7.76 & $-0.66 \quad 16.19$ & 0.071 & 7.56 & $-0.95 \quad 16.07$ & 0.082 \\
\hline \multicolumn{7}{|c|}{ Role Physical } \\
\hline Time 2 & 8.77 & $-4.67 \quad 22.22$ & 0.201 & 8.05 & $-5.45 \quad 21.55$ & 0.242 \\
\hline Time 4 & 6.85 & $-9.25 \quad 22.95$ & 0.405 & 7.96 & $-8.38 \quad 24.29$ & 0.340 \\
\hline \multicolumn{7}{|c|}{ Bodily Pain } \\
\hline Time 2 & 3.34 & -4.9511 .63 & 0.429 & 3.51 & -4.7611 .78 & 0.406 \\
\hline Time 4 & 4.76 & -5.1614 .67 & 0.347 & 3.63 & -6.3213 .59 & 0.474 \\
\hline \multicolumn{7}{|c|}{ General Health } \\
\hline Time 2 & -1.25 & $-7.98 \quad 5.47$ & 0.715 & -0.86 & $-7.63 \quad 5.90$ & 0.803 \\
\hline Time 4 & -1.95 & $-10.05 \quad 6.16$ & 0.638 & -3.52 & $-11.77 \quad 4.71$ & 0.401 \\
\hline \multicolumn{7}{|l|}{ Vitality } \\
\hline Time 2 & 1.42 & -5.958 .79 & 0.706 & 1.53 & -5.758 .80 & 0.681 \\
\hline Time 4 & 3.72 & -5.1512 .60 & 0.411 & 2.59 & -6.2611 .45 & 0.566 \\
\hline \multicolumn{7}{|c|}{ Social Functioning } \\
\hline Time 2 & 2.67 & -6.5611 .89 & 0.571 & 3.03 & -6.2912 .36 & 0.524 \\
\hline Time 4 & 4.86 & $\begin{array}{ll}-6.21 & 15.93 \\
\end{array}$ & 0.389 & 4.44 & -6.8515 .13 & 0.440 \\
\hline \multicolumn{7}{|c|}{ Role Emotional } \\
\hline Time 2 & 0.08 & -13.6013 .77 & 0.990 & 0.19 & $-13.49 \quad 13.86$ & 0.979 \\
\hline Time 4 & 0.72 & $-15.67 \quad 17.10$ & 0.932 & 0.65 & $-15.86 \quad 16.16$ & 0.938 \\
\hline \multicolumn{7}{|c|}{ Mental Health } \\
\hline Time 2 & 0.40 & $-5.95 \quad 6.76$ & 0.901 & 0.63 & $-5.74 \quad 7.02$ & 0.847 \\
\hline Time 4 & 1.97 & $\begin{array}{ll}-5.69 & 9.640\end{array}$ & 0.614 & 1.48 & $-6.30 \quad 9.67$ & 0.709 \\
\hline
\end{tabular}

and others, should be incorporated into the Dica Br program to improve cardiovascular outcomes. ${ }^{19}$

Appropriate dietary recommendations can play an essential part in the prevention and treatment of chronic diseases and consequently in the improvement of QoL. Authors have consistently demonstrated this association in intervention and observational studies. For example, in a randomized clinical trial with dietary intervention with postmenopausal women in the United States, with individual monitoring by a nutritionist and group consultations, showed a slight but significant improvement in the rates of quality of life. ${ }^{30}$ Another study, also in the United States, with obese adults of both sexes, with group consultations, dietary guidance and physical activity, showed an improvement in QoL of participants. ${ }^{35}$ There was an improvement in the QoL of our participants after four years of dietary intervention, with individual and group consultations. However, such improvement was not different as compared with the CG. 
Regarding the most studied dietary patterns, the Mediterranean pattern stands out in the scientific literature ${ }^{8,14,36,37}$ for its role in the prevention and treatment of CVD in many parts of the world, including Brazil. ${ }^{15,16,34,38,39}$ However, the foods that make up this diet are typical of countries bathed by the Mediterranean Sea and are not usually consumed in Brazil, where they are often expensive. With the clear objective of adapting the Mediterranean diet to Brazilian food standards, the Cardioprotective Diet study considered the access to food, the cost and the clear understanding of the program by the participants..$^{20}$ The nutritional strategy was an attempt to increase accessibility to the diet, by adapting the menu to cultural specifications and encouraging the consumption of local products. In addition to fruits and vegetables, the consumption of larger amounts of other cardioprotective foods was recommended. However, despite the recommendation to consume locally produced food, some participants may have considered it as a costly option, which may have contributed to drop-out or low adherence. The program, with individual and group consultations, telephone calls and a cookbook, with the intention of holding participants' attention and facilitating adherence to the program, was intended to prevent cardiac events - stroke, infarction, angina and death - and improve QoL of these patients. ${ }^{40}$ Also, the low adherence to the program and the advanced age of the participants may have contributed to a loss to follow-up of $58.3 \%$ at the end of four years (68.1\% in the IG and $48.5 \%$ in the CG), in contrast to other studies on dietary intervention in diabetic, hypertensive, dyslipidemic patients that showed lower loss rates. ${ }^{11,36}$

In a four-year cohort study with 2,376 elderly participants in Spain, Pérez-Tasigchana et al. observed that there was no association between high adherence to diet and improved QoL. ${ }^{14}$ Torres et al., ${ }^{41}$ in a study in Australia with 100 elderly women with a mean age of 60 years, evaluating the effects of a high-protein diet and physical activity program, showed that there was no significant difference in the QoL between intervention and control groups, despite the higher scores in the physical domains obtained by the group undergoing the high protein diet. ${ }^{41}$

We believe that the fact that these patients were already in tertiary prevention, that is, they had previously been advised about their diet, might be one of the factors that can explain the absence of significant difference between the CG and IG in our study.

The loss to follow-up was one of the main limitations of our study and may have been caused by the low level of education of the participants, which may have led to difficulties in understanding the program. Another possible contributing factor was the fact that they had atherosclerotic disease, often a limiting condition, considering the distance between their home and the hospital.

\section{Conclusion}

At the end of these four years of study, we could observe that the QoL of the participants improved, but we did not find any difference between the IG and the CG. There was also an improvement in the LDL-cholesterol fraction and total cholesterol in the IG, which did not occur in the CG. Participants in both groups had a reduction in WC, but apparently, it was not enough to decrease the cardiometabolic risk.

\section{Potential Conflict of Interest}

No potential conflict of interest relevant to this article was reported.

\section{Sources of Funding}

This study was funded by Hospital do Coração (HCor), as part of the Hospitals de Excellence in Health Services (PROADI-SUS), in partnership with the Ministry of Health of Brazil.

\section{Study Association}

This article is part of the thesis of master submitted by Patricia Regina Thomé Martins, from Instituto Nacional de Cardiologia.

\section{Ethics approval and consent to participate}

This study was approved by the Ethics Committee of the Instituto Nacional de Cardiologia and the Hospital Universitário Pedro Ernesto da Universidade do Estado do Rio de Janeiro under the protocol number 03218512.0.2006.5272 and 03218512.0.2002.5259, respectively. All the procedures in this study were in accordance with the 1975 Helsinki Declaration, updated in 2013. Informed consent was obtained from all participants included in the study. 


\section{Author contributions}

Conception and design of the research: Weber B, Moreira ASB. Acquisition of data: Martins PRT. Analysis and interpretation of the data: Martins PRT.

\section{References}

1. World Health Organization. Global recomendation on physical activity for health. Geneva: WHO; 2010.

2. Brasil. Ministério da Saúde. DATASUS. Óbitos por Residência por capítulo CID-10 segundo região [Internet]. Brasília: Ministério da Saúde; 2016 [cited 2021 Jun 4]. Available from: http://tabnet.datasus.gov.br/cgi/ tabcgi.exe?sim/cnv/obt10uf.def

3. Sociedade Brasileira de Cardiologia. Cardiômetro da Sociedade Brasileira de Cardiologia já registra mais de 10 mil mortes por doenças cardíacas nos primeiros dias do ano [Internet]. Rio de Janeiro: SBC; 2014. Available from: http://socios.cardiol.br/2014/20160119-cardiometro.asp

4. Darvishpour A, Javadi-Pashaki N, Salari A, Sadeghi T, Taleshan-Nejad M. Factors associated with quality of life in patients undergoing coronary angioplasty. Int J Health Sci (Qassim). 2017;11(4):35-41.

5. Del Castillo LNC, Leporace G, Cardinot TM, Levy RA, Oliveira LP. A importância dos questionários para avaliação da qualidade de vida. Rev Hosp Univ Pedro Ernesto. 2012;11:12-7.

6. Moriel G, Roscani MG, Matsubara LS, Cerqueira AT, Matsubara BB. Quality of life in patients with severe and stable coronary atherosclerotic disease. Arq Bras Cardiol. 2010;95(6):691-7. doi: 10.1590/s0066$782 \times 2010005000151$.

7. Ahmed HO, Ezzat RF. Quality of life of obese patients after treatment with the insertion of intra-gastric balloon versus Atkins diet in Sulaimani Governorate, Kurdistan Region, Iraq. Ann Med Surg (Lond). 2018;37:42-6. doi: 10.1016/j.amsu.2018.11.014.

8. Veronese N, Stubbs B, Noale M, Solmi M, Luchini C, Maggi S. Adherence to the Mediterranean diet is associated with better quality of life: data from the Osteoarthritis Initiative. Am J Clin Nutr. 2016;104(5):1403-9. doi: 10.3945/ajcn.116.136390

9. Vieira LP, Nobre MR, Queiroz GG. Eating behavior and nutritional status in patients who underwent coronary angioplasty. Nutr Hosp. 2012;27(1):281-7. doi: 10.1590/S0212-16112012000100038.

10. Mozaffarian D. Dietary and policy priorities for cardiovascular disease, diabetes, and obesity: a comprehensive review. Circulation. 2016;133(2):187-225. doi: 10.1161/CIRCULATIONAHA.115.018585.

11. Di Renzo L, Cioccoloni G, Falco S, Abenavoli L, Moia A, Salimei PS, et al. Influence of FTO rs9939609 and Mediterranean diet on body composition and weight loss: a randomized clinical trial. J Transl Med. 2018;16(1):308. doi: 10.1186/s12967-018-1680-7.

12. Alcubierre N, Martinez-Alonso M, Valls J, Rubinat E, Traveset A, Hernández M, et al. Relationship of the adherence to the Mediterranean diet with health-related quality of life and treatment satisfaction in patients with type 2 diabetes mellitus: a post-hoc analysis of a crosssectional study. Health Qual Life Outcomes. 2016;14:69. doi: 10.1186/ s12955-016-0473-z.

13. Estruch R, Martínez-González MA, Corella D, Salas-Salvadó J, RuizGutiérrez V, Covas MI, et al. Effects of a Mediterranean-style diet on cardiovascular risk factors: a randomized trial. Ann Intern Med. 2006;145(1):1-11. doi: 10.7326/0003-4819-145-1-200607040-00004.

14. Pérez-Tasigchana RF, León-Muñoz LM, López-García E, Banegas JR, Rodríguez-Artalejo F, Guallar-Castillón P. Mediterranean Diet and health-related quality of life in two cohorts of community-dwelling older adults. PLoS One. 2016;11(3):e0151596. doi: 10.1371/journal pone.0151596.
Statistical analysis: Martins PRT, Santos EM, Rodrigues Junior LF. Obtaining financing: Weber B. Writing of the manuscript: Martins PRT. Critical revision of the manuscript for intellectual content: Moreira ASB, Santos EM.

15. Mach F, Baigent C, Catapano AL, Koskinas KC, Casula M, Badimon L, et al. 2019 ESC/EAS Guidelines for the management of dyslipidaemias: lipid modification to reduce cardiovascular risk. Eur Heart J. 2020;41(1):111-88. doi: 10.1093/eurheartj/ehz455

16. Arnett DK, Blumenthal RS, Albert MA, Buroker AB, Goldberger ZD, Hahn EJ, et al. 2019 ACC/AHA Guideline on the Primary Prevention of Cardiovascular Disease: Executive Summary: a report of the American College of Cardiology/American Heart Association Task Force on Clinical Practice Guidelines. J Am Coll Cardiol. 2019;74(10):1376-414. doi: 10.1016/j.jacc.2019.03.009.

17. Bonaccio M, Di Castelnuovo A, Bonanni A, Costanzo S, De Lucia F, Pounis $\mathrm{G}$, et al. Adherence to a Mediterranean diet is associated with a better health-related quality of life: a possible role of high dietary antioxidant content. BMJ Open. 2013;3(8):e003003. doi: 10.1136/bmjopen-2013-003003.

18. Gopinath B, Russell J, Flood VM, Burlutsky G, Mitchell P. Adherence to dietary guidelines positively affects quality of life and functional status of older adults. J Acad Nutr Diet. 2014;114(2):220-9. doi: 10.1016/j. jand.2013.09.001.

19. Weber B, Bersch-Ferreira ÂC, Torreglosa CR, Marcadenti A, Lara ES, da Silva JT, et al. Implementation of a Brazilian Cardioprotective Nutritional (BALANCE) Program for improvement on quality of diet and secondary prevention of cardiovascular events: A randomized, multicenter trial. Am Heart J. 2019;215:187-97. doi: 10.1016/j.ahj.2019.06.010.

20. Weber B, Bersch-Ferreira ÂC, Torreglosa CR, Ross-Fernandes MB, Silva JT, Galante AP, et al. The Brazilian Cardioprotective Nutritional Program to reduce events and risk factors in secondary prevention for cardiovascular disease: study protocol (The BALANCE Program Trial). Am Heart J. 2016;171(1):73-81. doi: 10.1016/j.ahj.2015.08.010.

21. Weber B, Galante AP, Bersch-Ferreira AC, Torreglosa CR, Carvalho VO, Victor Eda S, et al. Effects of Brazilian Cardioprotective Diet Program on risk factors in patients with coronary heart disease: a Brazilian Cardioprotective Diet randomized pilot trial. Clinics (Sao Paulo). 2012;67(12):1407-14. doi: 10.6061/clinics/2012(12)10.

22. Silva JT, Bersch-Ferreira ÂC, Torreglosa CR, Weber B, Levy RB. Development of a dietary index based on the Brazilian Cardioprotective Nutritional Program (BALANCE). Nutr J. 2018;17(1):49. doi: 10.1186/ s12937-018-0359-5.

23. Drewnowski A. Concept of a nutritious food: toward a nutrient density score. Am J Clin Nutr. 2005;82(4):721-32. doi: 10.1093/ajcn/82.4.721.

24. Ciconelli RM, Ferraz MB, Santos W, Meinão I, Quaresma MR. Tradução para a língua portuguesa e validação do questionário genérico de avaliação de qualidade de vida SF-36 (Brasil SF-36). Rev Bras Reumatol. 1999;39(3):143-50

25. Garratt AM, Ruta DA, Abdalla MI, Buckingham JK, Russell IT. The SF36 health survey questionnaire: an outcome measure suitable for routine use within the NHS? BMJ. 1993;306(6890):1440-4. doi: 10.1136/ bmj.306.6890.144

26. Myers ND, Brincks AM, Ames AJ, Prado GJ, Penedo FJ, Benedict C. Multilevel modeling in psychosomatic medicine research. Psychosom Med. 2012;74(9):925-36. doi: 10.1097/PSY.0b013e3182736971.

27. Kwok OM, Underhill AT, Berry JW, Luo W, Elliott TR, Yoon M. Analyzing longitudinal data with multilevel models: an example with individuals living with lower extremity intra-articular fractures. Rehabil Psychol. 2008;53(3):370-86. doi: 10.1037/a0012765. 
28. Sanchez-Aguadero N, Alonso-Dominguez R, Garcia-Ortiz L, AgudoConde C, Rodriguez-Martin C, Cabo-Laso A, et al. Diet and physical activity in people with intermediate cardiovascular risk and their relationship with the health-related quality of life: results from the MARK study. Health Qual Life Outcomes. 2016;14(1):169. doi: 10.1186/ s12955-016-0572-x.

29. Guldbrand H, Lindström T, Dizdar B, Bunjaku B, Östgren CJ, Nystrom $\mathrm{FH}$, et al. Randomization to a low-carbohydrate diet advice improves health related quality of life compared with a low-fat diet at similar weight-loss in type 2 diabetes mellitus. Diabetes Res Clin Pract. 2014;106(2):221-7. doi: 10.1016/j.diabres.2014.08.032.

30. Assaf AR, Beresford SA, Risica PM, Aragaki A, Brunner RL, Bowen DJ, et al. Low-fat dietary pattern intervention and health-related quality of life: the women's health initiative randomized controlled dietary modification trial. J Acad Nutr Diet. 2016;116(2):259-71. doi: 10.1016/j.jand.2015.07.016.

31. Milte CM, Thorpe MG, Crawford D, Ball K, McNaughton SA. Associations of diet quality with health-related quality of life in older Australian men and women. Exp Gerontol. 2015;64:8-16. doi: 10.1016/j. exger.2015.01.047.

32. Jahangiry L, Montazeri A, Najafi M, Yaseri M, Farhangi MA. An interactive web-based intervention on nutritional status, physical activity and health-related quality of life in patient with metabolic syndrome: a randomized-controlled trial (The Red Ruby Study). Nutr Diabetes. 2017;7(1):240. doi: 10.1038/nutd.2016.35.

33. Castres I, Tourny C, Lemaitre F, Coquart J. Impact of a walking program of 10,000 steps per day and dietary counseling on health-related quality of life, energy expenditure and anthropometric parameters in obese subjects. J Endocrinol Invest. 2017;40(2):135-41. doi: 10.1007/s40618-016-0530-9.

34. Précoma DB, Oliveira GMM, Simão AF, Dutra OP, Coelho OR, Izar MCO, et al. Updated Cardiovascular Prevention Guideline of the Brazilian
Society of Cardiology - 2019. Arq Bras Cardiol. 2019;113(4):787-891. doi: 10.5935/abc.20190204.

35. Martin CK, Bhapkar M, Pittas AG, Pieper CF, Das SK, Williamson DA et al. Effect of calorie restriction on mood, quality of life, sleep, and sexual function in healthy nonobese adults: The CALERIE 2 randomized clinical trial. JAMA Intern Med. 2016;176(6):743-52. doi: 10.1001/ jamainternmed.2016.

36. Landaeta-Díaz L, Fernández JM, Silva-Grigoletto M, Rosado-Alvarez D, Gómez-Garduño A, Gómez-Delgado F, et al. Mediterranean diet, moderate-to-high intensity training, and health-related quality of life in adults with metabolic syndrome. Eur J Prev Cardiol. 2013;20(4):555-64. doi: $10.1177 / 2047487312445000$.

37. Ruano C, Henriquez P, Martínez-González MÁ, Bes-Rastrollo M, Ruiz-Canela M, Sánchez-Villegas A. Empirically derived dietary patterns and health-related quality of life in the SUN project. PLoS One. 2013;8(5):e61490. doi: 10.1371/journal.pone.0061490.

38. Faludi AA, Izar MCO, Saraiva JFK, Chacra APM, Bianco HT, Afiune A Neto, et al. Atualização da diretriz brasileira de dislipidemias e prevenção da Aterosclerose - 2017. Arq Bras Cardiol. 2017;109(2 Supl 1):1-76. doi: 10.5935/abc. 20170121.

39. Faludi AA, Izar MCO, Saraiva JFK, Chacra APM, Bianco HT, Afiune A Neto, et al. Atualização da Diretriz Brasileira de Dislipidemias e Prevenção da Aterosclerose - 2017. Arq Bras Cardiol. 2017;109(2 Supl 1):1-76. doi: 10.5935/abc.20170121.

40. Torres SJ, Robinson S, Orellana L, O'Connell SL, Grimes CA, Mundell NL, et al. Effects of progressive resistance training combined with a proteinenriched lean red meat diet on health-related quality of life in elderly women: secondary analysis of a 4-month cluster randomised controlled trial. Br J Nutr. 2017;117(11):1550-9. doi: 10.1017/S0007114517001507. 